\title{
Studies of properties of "Pain Networks" as predictors of targets of stimulation for treatment of pain
}

\author{
C. C. Liu ${ }^{1}$, P. Franaszczuk ${ }^{2,3}$, N. E. Crone ${ }^{2}$, C. Jouny ${ }^{2}$ and F. A. Lenz ${ }^{1 *}$ \\ ${ }^{1}$ Department of Neurosurgery, Johns Hopkins Hospital, Baltimore, MD, USA \\ ${ }^{2}$ Department of Neurology, Johns Hopkins Hospital, Baltimore, MD, USA \\ ${ }^{3}$ US Army Research Laboratory, Human Research and Engineering Directorate, Aberdeen Proving Ground, MD, USA
}

Edited by:

Sridevi V. Sarma, Johns Hopkins

University, USA

\section{Reviewed by:}

Dante R. Chialvo, Northwestern

University, USA

Guillermo A. Cecchi, IBM Watson

Research Center, USA

*Correspondence:

F. A. Lenz, Department of

Neurosurgery, Johns Hopkins

Hospital, Meyer Building 8-181,

600 North Wolfe Street,

Baltimore, MD 21287-7713, USA

e-mail: flenz1@jhmi.edu
Two decades of functional imaging studies have demonstrated pain-related activations of primary somatic sensory cortex (S1), parasylvian cortical structures (PS), and medial frontal cortical structures (MF), which are often described as modules in a "pain network." The directionality and temporal dynamics of interactions between and within the cortical and thalamic modules are uncertain. We now describe our studies of these interactions based upon recordings of local field potentials (LFPs) carried out in an epilepsy monitoring unit over the one week period between the implantation and removal of cortical electrodes during the surgical treatment of epilepsy. These recordings have unprecedented clarity and resolution for the study of LFPs related to the experimental pain induced by cutaneous application of a Thulium YAG laser. We also used attention and distraction as behavioral probes to study the psychophysics and neuroscience of the cortical "pain network." In these studies, electrical activation of cortex was measured by event-related desynchronization (ERD), over SI, PS, and MF modules, and was more widespread and intense while attending to painful stimuli than while being distracted from them. This difference was particularly prominent over PS. In addition, greater perceived intensity of painful stimuli was associated with more widespread and intense ERD. Connectivity of these modules was then examined for dynamic causal interactions within and between modules by using the Granger causality (GRC). Prior to the laser stimuli, a task involving attention to the painful stimulus consistently increased the number of event-related causality (ERC) pairs both within the SI cortex, and from SI upon PS (SI > PS). After the laser stimulus, attention to a painful stimulus increased the number of ERC pairs from $\mathrm{SI}>\mathrm{PS}$, and $\mathrm{SI}>\mathrm{MF}$, and within the SI module. LFP at some electrode sites (critical sites) exerted ERC influences upon signals at multiple widespread electrodes, both in other cortical modules and within the module where the critical site was located. In summary, critical sites and SI modules may bind the cortical modules together into a "pain network," and disruption of that network by stimulation might be used to treat pain. These results in humans may be uniquely useful to design and optimize anatomically based pain therapies, such as stimulation of the S1 or critical sites through transcutaneous magnetic fields or implanted electrodes.

Keywords: pain networks, stimulation, treatment of pain, local field potentials

\section{INTRODUCTION}

Over the past three decades, functional imaging studies have led to the model that pain is a complex experience that is associated with increased blood flow or BOLD signals in multiple structures in the brain (Davis, 2000; Derbyshire, 2000; Rainville et al., 2000; Apkarian et al., 2005; Lenz et al., 2010). These structures have been characterized as a "pain network" or "neuro-matrix" (Melzack, 1990; Gelnar et al., 1999; Peyron et al., 1999; Casey, 2000; Strigo et al., 2003), rather than as a collection of unrelated centers (Melzack and Casey, 1968). A network consists of neural elements, their connections, and connectional weights, which are often equated respectively, with neurons/modules in the brain, axons, and synapses. Functional interactions within such a network may be conceived of as the network properties that enable its modules jointly to process inputs or outputs, or both.

The pain network includes cortical modules such as the medial frontal cortex (MF including anterior and middle cingulate cortex-ACC and MCC, and supplementary motor area-SMA), the primary sensory cortex (S1), and the parasylvian structures (PS including opercular and insular cortex) (Casey, 2000; Davis, 2000; Apkarian et al., 2005; Lenz et al., 2010). We now review our studies of the thalamic and cortical structures which mediate the effect of acute pain. We will review our evidence that these structures are characterized by the response to painful stimuli (Lee et al., 1999; Ohara et al., 2004b,c; Kobayashi et al., 2009), by the analgesic effect of thalamic and cortical lesions 
(Greenspan et al., 1999, 2008; Kim et al., 2007; Veldhuijzen et al., 2009), and by the painful sensations evoked by thalamic stimulation (Lenz et al., 1993, 2004; Ohara and Lenz, 2003; Patel et al., 2006). Based upon this evidence cortical (S1, PS, and MF) and thalamic modules may subserve different components of the sensation of pain.

Pain is commonly viewed as a sensation composed of multiple components which are mediated through a network (Melzack, 1990; Gelnar et al., 1999; Peyron et al., 1999; Casey, 2000; Strigo et al., 2003). However, there is evidence from functional imaging studies that cortical modules are local networks that are associated with different dimensions of pain. We now review psychophysical studies of patients with forebrain lesions, and our studies of interactions between signals recorded from different structures in the brain.

Studies of lesions by our group and others, demonstrate double dissociation of functions that are impaired following lesions of modules, or local networks. These modules with their corresponding dimension of pain include: (1) somatic sensory thalamus and parietal cortex with the sensory dimension (Ploner et al., 1999; Rainville et al., 1999; Hofbauer et al., 2001; Greenspan et al., 2004, 2008; Montes et al., 2005; Kim et al., 2007), (2) the insula with decreased pain tolerance (Greenspan et al., 1999; Starr et al., 2009; Veldhuijzen et al., 2009), and (3) the MCC with decreased gain of pain ratings (Davis et al., 1994; Talbot et al., 1995; Greenspan et al., 2008).

These widespread, functional interactions between local networks or modules in the brain (Ohara et al., 2004a, 2006, 2008; Greenspan et al., 2008), may explain the binding of different dimensions of pain together to produce a unified pain sensation (Singer and Gray, 1995). In particular, functional interactions of this type have been related to a number of cognitive tasks in humans (von der Malsburg, 1995). Long range synchrony is often related to the lower frequency range, as in the case of the present study (Rodriguez et al., 1999). This type of organization is well established in language networks in which normal language requires a network composed of modules subserving "speech production (frontal lobe)," and "speech reception" (temporal-parietal lobe), and their interconnections (Churchland and Sejnowski, 1992; Arbib, 2002; Korzeniewska et al., 2008).

\section{THE "PAIN NETWORK" AND STIMULATION EVOKED ANALGESIA}

Studies of the human "pain network" have fundamentally altered our concepts of both the "pain network," and the treatment of pain by stimulation of that network (Coffey and Lozano, 2006; Lenz, 2006; Cruccu et al., 2007; Dorsi and Lenz, in press). At present, these stimulation therapies include: (1) transcutaneous magnetic stimulation (TMS) of the motor cortex or dorsal lateral prefrontal cortex (Leo and Latif, 2007; Wassermann et al., 2010), or (2) electrical stimulation at sites including the thalamus (Schuurman et al., 2000; Rasche et al., 2006), or motor cortex (Fontaine et al., 2008). Our more recent studies seek to predict effective stimulation sites based on their widespread causal influence upon other modules in the "pain network." The present manuscript will examine the results of recent studies of functional connectivity within the thalamic and cortical modules in the "pain network." If the location of cortical targets is consistent across patients using this approach, then new targets for stimulation could be rapidly applied to protocols of TMS. Our studies have been carried out with refinements of techniques employed during previous studies, as reviewed below.

\section{TECHNICAL FACTORS IN THE ANALYSIS OF THE "PAIN NETWORK"}

The "pain network" has previously been studied by fMRI signals analyzed by techniques focusing on the pre-stimulus interval or a fixed cognitive task/set (Kong et al., 2006, 2010; Boly et al., 2007). These prior technical approaches to pain-related functional interactions are complicated by long sampling intervals and widespread modules. Perhaps because of these difficulties, the "pain network" is usually assumed to be static, or fixed across time and task (Melzack, 1990; Peyron et al., 1999; Price, 2000; Apkarian et al., 2005). Our recent studies have overcome these technical difficulties (Ohara et al., 2004a, 2006, 2008; Zygierewicz et al., 2005, 2006; Korzeniewska et al., 2008; Liu et al., 2010), and have demonstrated that the pain networks composed of structures which are activated by painful stimuli are not static but dynamic and task specific (Ohara et al., 2004a, 2006, 2008; Apkarian and Chialvo, 2006; Liu et al., 2010).

The techniques used in our recent studies represent techni$\mathrm{cal}$ and theoretical advances in the study of human forebrain pain-related networks. The resolution of our recordings made directly from the human brain have the unprecedented temporal and spatial resolution of thalamic neuronal spike trains $(500 \mathrm{~Hz}$, $<0.5 \mathrm{~mm}$ ), and recordings of multiple neurons (local field potentials, LFPs) in the cortex $(200 \mathrm{~Hz},<1 \mathrm{~cm})$ and the thalamus (200 Hz, 2-3 mm, Figure 4). In comparison, current techniques for the study of human pain-related networks include Positron Emission Tomography (PET) $(\ll 1 \mathrm{~Hz},>1 \mathrm{~cm})$, fMRI $(<1 \mathrm{~Hz}$, $>3 \mathrm{~mm}$ ) (Kong et al., 2010), and scalp EEG (scalp EEG $80 \mathrm{~Hz}$, $>5 \mathrm{~cm}$ ). Therefore, our recent studies have a broader bandwidth, a higher temporal resolution, and an increased spatial resolution than previous studies (Kong et al., 2006, 2010; Boly et al., 2007; Ploner et al., 2009).

These recording techniques yield high resolution signals which are analyzed by using the multivariate autoregressive models. Granger adopted the idea of causality introduced by Wiener and established the causality measure called Granger causality (GRC) (Weiner, 1956; Granger, 1969). The event-related causality (ERC) used in our studies for determining the significant interactions among different brain structures was based the same concept as GRC. ERC fulfills the following three conditions: (1) The changes in X predict $Y,(2)$ The changes in X precede $Y$, and (3) when evaluating the causal influences between $\mathrm{X}$ and $\mathrm{Y}, \mathrm{ERC}$ analysis take into account the changes in $\mathrm{X}$ and $\mathrm{Y}$ that are contributed by all other variables in the system. Therefore, under some suitable statistical sense, we conclude that $\mathrm{X}$ is granger causal Y. However, we have to keep in mind that the observed ERC might arise from the unobserved sources in the system.

Recent advances have enabled the evaluation of the short time ERC in a multivariate system. ERC is a multivariate approach and is based on the Short-time direct Directed Transfer Function 
(SdDTF) for estimating the changes the direct causal interactions within a multivariate system that are event-related in the frequency domain. The SdDTF is used for the signals that are short in duration and have a large number of repetitions. The essential part of the ERC method is the statistical testing procedure which will reveal the significant changes in interchannel relationships that are event-related (Ding et al., 2000; Korzeniewska et al., 2003; Liu et al., 2011a). We now review our studies of functional connectivity including those employing the ERC techniques described above.

\section{CORTICAL MODULES IN THE "PAIN NETWORK"}

Our studies have demonstrated that the functional connectivity between S1, PS, and MF changes dynamically with task, such as the anticipation of the laser stimulus, versus attention to the laser versus distraction from the laser (Ohara et al., 2004a,d, 2006, 2008). We considered that the human "pain network" included cortical areas which are activated during the response to painful stimuli (termed category 1), or during psychological processes which modulate pain, such as distraction (termed category 2) (Liu et al., 2011c). Among category 1 areas prior to the laser stimuli, directed attention to the painful stimulus (counting) consistently increased the number of ERC pairs both within the SI cortex, and from SI upon PS (SI > PS) (Liu et al., 2011b,c). After the laser stimulus, attention to a painful stimulus increased the number of ERC pairs from SI $>$ PS, and SI $>$ MF, and within the SI area. LFP at some electrode sites (critical sites) exerted ERC influences upon signals at multiple widespread electrodes, both in other cortical areas and within the area where the critical site was located. Therefore, the number of electrodes involved in pairs with significant ERC in category 1 was greater for pre-stimulus versus post-stimulus period and for attention versus distraction, which is consistent with a network in which functional connections change rapidly with intervals and tasks.

In contrast, the interaction between categories 1 and 2 was often unchanged or stable across intervals and tasks, particularly in MF (Liu et al., 2011c). Functional interactions between categories were overwhelmingly in the direction from category $2>1$, particularly for contacts in MF which often had a driver role. Therefore, some functional interactions within the pain network may be dynamic while others are apparently static. These temporal factors in the "pain network" and modules may clarify important parameters of the system such as the time course of pain stimuli, of attentive tasks, and of therapeutic stimulation. We next considered the MF module which has the largest number of causal interactions in the "pain network," and so may play a pivotal role in the network.

\section{THE MF MODULE IS PIVOTAL IN THE "PAIN NETWORK"}

Our most recent studies have identified MF as the most critical module in the "pain network." The participation of MCC in pain processing is suggested by activation of this area in response to acute pain (Davis et al., 1997; Derbyshire et al., 1998). The extent of pain-related function along the caudal-rostral axis of MCC and ACC is suggested by functional imaging studies demonstrating widespread blood flow or BOLD activation between individuals (Davis et al., 1997; Derbyshire et al., 1998). Cingulate generators of laser evoked potentials (LEPs) are supported by source analysis of scalp EEG (Tarkka and Treede, 1993; Chen and Bromm, 1995; Kitamura et al., 1995; Valeriani et al., 1996); recordings directly from the surface of the cortex localize the generator in the MCC, just anterior to the M1 (Lenz et al., 1998; Rios et al., 1999; Ohara et al., 2004c).

Attention-related tasks (e.g., verbal fluency or Stroop) will also activate widespread MF areas (Davis et al., 1997; Derbyshire et al., 1998). Direct comparisons identify interleaved subunits within the ACC and MCC which are activated by attention versus painrelated tasks (Ploghaus et al., 1999). Therefore, the present results may be the result of widespread functionally discrete subunits or modules in MF which subserve pain and attention.

In comparison with other cortical areas, MF accounts for the largest number of contacts involved in consistent causal pairs, particularly in the case of attention and category $2>$ category 1 interactions (Liu et al., 2011c). These consistent connections were often stable across time intervals and attentional tasks. Furthermore, functional interactions from category $2>$ category 1 within the same cortical category were only found for MF (Davis et al., 1997; Derbyshire et al., 1998). These results strongly suggest that MF is the pivotal cortical module in the "pain network." Interactions of cortical and thalamic modules are also likely to play a pivotal role as reviewed below.

\section{CORTICO-THALAMIC ASSEMBLIES IN THE "PAIN NETWORK"}

Thalamic structures are likely modules in the "pain network," based on their involvement in densely inter-connected thalamo-cortical assemblies (Steriade et al., 1997b; Destexhe and Sejnowski, 2001) so that it is not possible to understand the function of one without the other (Steriade et al., 1997a; Destexhe and Sejnowski, 2001; Sherman and Guillery, 2001). Cortico-cortical synchrony may be related to interactions with thalamic modules by mechanisms including common input from thalamic to cortical modules, or thalamic oscillations which may be either intrinsic or related to afferent volleys (Burton, 1975, 1984; Apkarian and Shi, 1994).

Thalamic neuronal I (intermediate, mixed single spikes, and bursts) category firing is more likely than other categories: (1) to show a response to laser stimuli (Kobayashi et al., 2009), (2) to change category when the cognitive task changes (Kim et al., 2009), and (3) to have synchrony with cortical modules. Therefore, I category firing may be a selective carrier of pain-related signals which is influenced by changes in cognitive tasks (Kim et al., 2009), and which may enable both the thalamic response to the laser and the transmission of that response to the cortex. Furthermore, I category firing is associated with inhibitory events of GABAb duration leading to low threshold spike LTS bursts (Ohara et al., 2007; Kim et al., 2009), which might be exploited by pharmacological therapies targeting thalamic GABAergic transmission (Bal et al., 1995; Rudolph and Mohler, 2006; Agid et al., 2007; Mohler et al., 2008; Kim et al., 2009), and possibly LTS channels (Huguenard and Prince, 1994; Porcello et al., 2003; Barton et al., 2005; Fischer and Waxman, 2010). Selective attention and learning may be increased by some of the newer GABAergic agonists; these agents might have analgesic properties, 
or might augment behavioral therapies (Mohler, 2009) based upon their ability to influence I category firing. The connection of different modules in the "pain network" suggests strategies for analgesic stimulation of the brain, which are considered below.

\section{STRATEGIES FOR IDENTIFYING ANALGESIC STIMULATION SITES}

The efficacy of stimulation therapies may result from activation and disruption of a single module (Desmurget et al., 2009; Sirigu et al., 2010), or from activation of a network by stimulation of either a single module (Desmurget et al., 2009; Karnath et al., 2010; Sirigu et al., 2010) or a subcortical white matter pathway (De et al., 2007; Herbsman et al., 2009; Karnath et al., 2010). In psychiatric disease, effective stimulation disrupts a widespread network as measured by the extent of stimulation-evoked change on cognitive testing (Levit-Binnun et al., 2007), and of activation plus functional connectivity in functional imaging studies (Shajahan et al., 2002).

At present, the motor cortex is the most common site for stimulation for pain based upon studies in animal models (Tsubokawa et al., 1987). Its efficacy has been demonstrated in clinical studies of both electrical (Tsubokawa et al., 1991; Brown and Barbaro, 2003) and magnetic stimulation (Wassermann and Lisanby, 2001; Lefaucher, 2008), although other frontal (Borckardt et al., 2006, 2007; Fierro et al., 2010) or parietal stimulation sites may have much greater therapeutic effects (Topper et al., 2003; Fregni et al., 2005).

Stimulation targeting modules in the "pain network" for the treatment of different types of pain, such as post-operative pain (Borckardt et al., 2006) and chronic pain (Wassermann et al., 2010). This organization of therapeutic effects could be as revolutionary as deep brain stimulation of the different modules in the basal ganglia network for the treatment of different movement disorders (Wichmann and DeLong, 1996; Walter and Vitek, 2004; Anderson and Lenz, 2006). The basal ganglia model in patients with movement disorders differs from that in healthy individuals by the magnitude but not by the direction of causal influences, which suggests that the proposed studies of acute pain might describe functional interactions in a network which is relevant to chronic pain.

Studies of signals recorded simultaneously from the thalamus and cortex are important given the poorly understood interaction

\section{REFERENCES}

Agid, Y., Buzsaki, G., Diamond, D. M., Frackowiak, R., Giedd, J., Girault, J. A., Grace, A., Lambert, J. J., Manji, H., Mayberg, H., Popoli, M., Prochiantz, A., Richter-Levin, G., Somogyi, P., Spedding, M., Svenningsson, P., and Weinberger, D. (2007). How can drug discovery for psychiatric disorders be improved? Nat. Rev. Drug Discov. 6, 189-201.

Anderson, W. S., and Lenz, F. A. (2006). Surgery insight: deep brain stimulation for movement disor- ders. Nat. Clin. Pract. Neurol. 2, 310-320.

Apkarian, A. V., Bushnell, M. C., Treede, R.-D., and Zubieta, J. K. (2005). Human brain mechanisms of pain perception and regulation in health and disease. Eur. J. Pain 9, 463-484.

Apkarian, A. V., and Chialvo, D. R. (2006). The shadows of pain. Pain 123, 221-222.

Apkarian, A. V., and Shi, T. (1994). Squirrel monkey lateral thalamus. I. somatic nociresponsive neurons and their relation of these structures in pain networks. Our ongoing studies of activation and causality may also allow us to suggest synaptic mechanisms which mediate functional interactions in the "pain network." If the GRC suggests that structure A exerts a causal influence upon structure B, then an increase in activation of both $A$ and $B$ suggests that this influence is excitatory.

If activation of $\mathrm{A}$ is increased as that of $\mathrm{B}$ is decreased, then the influence may be inhibitory. If activation of $\mathrm{A}$ is decreased while that of $B$ is increased and the GRC influence from A to $\mathrm{B}$ diminishes, then the activation of $\mathrm{B}$ may be the result of disinhibition, i.e., decreased inhibition of B. For example, cortical output increases the activity of thalamic nucleus reticularis, which inhibits and so may decrease the activity of local circuit inhibitory interneurons, which leads to decreased inhibition of the activity of thalamocortical neurons, i.e., disinhibition (Steriade et al., 1997a; Sherman and Guillery, 2001).

Our electrophysiological studies have demonstrated that, PS showed decreased activation but increased functional interactions during distraction, while during attention increased activation was associated with decreased interactions. This suggests that an increased inhibitory process mediates the effect of distraction while disinhibition mediates the increased activation of attention.

Modulation of activity in PS by input from MF has been suggested by our prior psychophysical and PET study of the response to painful stimuli before and after a bilateral cingulotomy of the MCC. Following the cingulate lesion, there was an increase in pain ratings and increased activation of the parietal and insular cortex ipsilateral to a painful stimulus (Greenspan et al., 2008). In view of the present results, cingulate lesions or stimulation may produce activation through disinhibition of PS, and the effect of attention may occur through a similar disinhibitory process, which is dependent upon MCC (Greenspan et al., 2008). These studies point to the presence of functional interactions which may lead to complex patterns of response to stimulation delivered to produce an analgesic effect.

\section{ACKNOWLEDGMENTS}

This work was supported by the National Institutes of HealthNational Institute of Neurological Disorders and Stroke RO1s NS38493 and NS40059 to F. A. Lenz, NS040596 to N. E. Crone, NS-xxxx, to C. Jouny. We thank C. Cordes and L. H. Rowland for excellent technical assistance. to spinothalamic terminals. $J$. Neurosci. 14, 6779-6795.

Arbib, M. A. (2002). The Handbook of Brain Theory and Neural Networks. Cambridge, MA: MIT Press.

Bal, T., von Krosigk, M., and McCormick, D. A. (1995). Synaptic and membrane mechanisms underlying synchronized oscillations in the ferret lateral geniculate nucleus in vitro. J. Physiol. 483( $\mathrm{Pt} 3)$, 641-663.

Barton, M. E., Eberle, E. L., and Shannon, H. E. (2005). The antihyperalgesic effects of the T-type calcium channel blockers ethosuximide, trimethadione, and mibefradil. Eur. J. Pharmacol. 521, 79-85.

Boly, M., Balteau, E., Schnakers, C., Degueldre, C., Moonen, G., Luxen, A., Phillips, C., Peigneux, P., Maquet, P., and Laureys, S. (2007). Baseline brain activity fluctuations predict somatosensory perception in humans. Proc. Natl. Acad. Sci. U.S.A. 104, 12187-12192.

Borckardt, J. J., Smith, A. R., Reeves, S. T., Weinstein, M., Kozel, F. A., Nahas, Z., Shelley, N., Branham, 
R. K., Thomas, K. J., and George, M. S. (2007). Fifteen minutes of left prefrontal repetitive transcranial magnetic stimulation acutely increases thermal pain thresholds in healthy adults. Pain Res. Manag. 12, 287-290.

Borckardt, J. J., Weinstein, M., Reeves, S. T., Kozel, F. A., Nahas, Z., Smith, A. R., Byrne, T. K., Morgan, K., and George, M. S. (2006). Postoperative left prefrontal repetitive transcranial magnetic stimulation reduces patient-controlled analgesia use. Anesthesiology 105, 557-562.

Brown, J. A., and Barbaro, N. M. (2003). Motor cortex stimulation for central and neuropathic pain: current status. Pain 104, 431-435.

Burton, H. (1975). Responses of spinal cord neurons to systematic changes in hindlimb skin temperatures in cats and primates. J. Neurophysiol. 38, 1060-1079.

Burton, H. (1984). Corticothalamic connections from the second somatosensory area and neighboring regions in the lateral sulcus of macaque monkeys. Brain Res. 309, 367-372.

Casey, K. L. (2000). Concepts of pain mechanisms: the contribution of functional imaging of the human brain. Prog. Brain Res. 129, 277-287.

Chen, A. C.N., and Bromm, B. (1995). "Pain-related generators of laserevoked brain potentials: brain mapping and dipole modeling," in Pain and the Brain: From Nociception to Cognition, eds B. Bromm and J. E. Desmedt (New York: Raven Press), 245-266.

Churchland, P. S., and Sejnowski, T. J. (1992). The Computational Brain. Cambridge, MA: MIT Press.

Coffey, R. J., and Lozano, A. M. (2006). Neurostimulation for chronic noncancer pain: an evaluation of the clinical evidence and recommendations for future trial designs. J. Neurosurg. 105, 175-189.

Cruccu, G., Aziz, T. Z., Garcia-Larrea, L., Hansson, P., Jensen, T. S., Lefaucheur, J. P., Simpson, B. A., and Taylor, R. S. (2007). EFNS guidelines on neurostimulation therapy for neuropathic pain. Eur. J. Neurol. 14, 952-970.

Davis, K. D. (2000). "Studies of pain using functional magnetic resonance imaging", in Pain Imaging, eds K. L. Casey and M. C. Bushnell (Seattle, WA: IASP Press), 195-210.

Davis, K. D., Hutchison, W. D., Lozano, A. M., and Dostrovsky, J. O. (1994). Altered pain and temperature perception following cingulotomy and capsulotomy in a patient with schizoaffective disorder. Pain 59, 189-199.

Davis, K. D., Taylor, S. J., Crawley, A. P., Wood, M. L., Mikulis, D. J. (1997). Functional MRI of pain- and attention related activation in the human cingulate cortex. J. Neurophysiol. 77, 3370-3380.

De, L. M., Parker, G. J., Embleton, K., Newton, J. M., and Walsh, V. (2007). Diffusion tensor MRI-based estimation of the influence of brain tissue anisotropy on the effects of transcranial magnetic stimulation. Neuroimage 36, 1159-1170.

Derbyshire, S. W. (2000). Exploring the pain "neuromatrix". Curr. Rev. Pain 4, 467-477.

Derbyshire, S. W.G., Vogt, B. A., and Jones, A. K.P. (1998). Pain and stroop interference tasks activate separate processing modules in anterior cingulate cortex. Exp. Brain Res. 118, 52-60.

Desmurget, M., Reilly, K. T., Richard, N., Szathmari, A., Mottolese, C., and Sirigu, A. (2009). Movement intention after parietal cortex stimulation in humans. Science 324, 811-813.

Destexhe, A., and Sejnowski, T. J. (2001). Thalamcortical Assemblies. New York, NY: Oxford University Press.

Ding, M., Bressler, S. L., Yang, W., and Liang, H. (2000). Short-window spectral analysis of cortical eventrelated potentials by adaptive multivariate autoregressive modeling: data preprocessing, model validation, and variability assessment. Biol. Cybern. 83, 35-45.

Dorsi, M. J., and Lenz, F. A. (in press). "Neurosurgical approaches to the treatment of pain," in Wall and Melzack's Textbook of Pain, eds S. McMahon and M. Kotzenberg (New York, NY: Churchill and Livingstone).

Fierro, B., De, T. M., Giglia, F., Giglia, G., Palermo, A., and Brighina, F. (2010). Repetitive transcranial magnetic stimulation (rTMS) of the dorsolateral prefrontal cortex (DLPFC) during capsaicin-induced pain: modulatory effects on motor cortex excitability. Exp. Brain Res. 203, 31-38.

Fischer, T. Z., and Waxman, S. G. (2010). Neuropathic pain in diabetes - evidence for a central mechanism. Nat. Rev. Neurol. 6, 462-466.

Fontaine, D., Hamani, C., and Lozano, A. (2008). Efficacy and safety of motor cortex stimulation for chronic neuropathic pain: critical review of the literature. J. Neurosurg. $110,251-256$.
Fregni, F., DaSilva, D., Potvin, K., Ramos-Estebanez, C., Cohen, D., Pascual-Leone, A., and Freedman, S. D. (2005). Treatment of chronic visceral pain with brain stimulation. Ann. Neurol. 58, 971-972.

Gelnar, P. A., Krauss, B. R., Sheehe, P. R., Szeverenyi, N. M., and Apkarian, A. V. (1999). A comparative fMRI study of cortical representations for thermal painful, vibrotactile, and motor performance tasks. Neuroimage 10, 460-482.

Granger, C. W. (1969). Investigating causal relations by econometric models and cross spectral methods. Econometrica 37, 424-438.

Greenspan, J. D., Coghill, R. C., Gilron, I., Sarlani, E., Veldhuijzen, D., and Lenz, F. A. (2008). Quantitative somatic sensory testing and functional imaging of the response to painful stimuli before and after cingulotomy for obsessive compulsive disorder (OCD). Eur. J. Pain 12, 990-999.

Greenspan, J. D., Lee, R. R., and Lenz, F. A. (1999). Pain sensitivity alterations as a function of lesion location in the parasylvian cortex. Pain 81, 273-282.

Greenspan, J. D., Ohara, S., Sarlani, E. and Lenz, F. A. (2004). Allodynia in patients with post-stroke central pain (CPSP) studied by statistical quantitative sensory testing within individuals. Pain 109, 357-366.

Herbsman, T., Forster, L., Molnar, C. Dougherty, R., Christie, D., Koola, J., Ramsey, D., Morgan, P. S., Bohning, D. E., George, M. S., and Nahas, Z. (2009). Motor threshold in transcranial magnetic stimulation: the impact of white matter fiber orientation and skull-to-cortex distance. Hum. Brain Mapp. 30, 2044-2055.

Hofbauer, R. K., Rainville, P., Duncan, G. H., and Bushnell, M. C. (2001). Cortical representation of the sensory dimension of pain. $J$. Neurophysiol. 86, 402-411.

Huguenard, J. R., and Prince, D. A. (1994). Intrathalamic rhythmicity studied in vitro: nominal T-current modulation causes robust antioscillatory effects. J. Neurosci. 14, 5485-5502.

Karnath, H. O., Borchers, S., and Himmelbach, M. (2010). Comment on "movement intention after parietal cortex stimulation in humans". Science 327, 1200

Kim, J. H., Greenspan, J. D., Coghill, R. C., Ohara, S., and Lenz, F. A. (2007). Lesions limited to the human thalamic principal somatosensory nucleus (ventral caudal) are associated with loss of cold sensations and central pain. J. Neurosci. 27, 4995-5004.

Kim, J. H., Ohara, S., and Lenz, F. A. (2009). Mental arithmetic leads to multiple discrete changes from baseline in the firing patterns of human thalamic neurons. J. Neurophysiol. 101, 2107-2119.

Kitamura, Y., Kakigi, R., Hoshiyama, M., Koyama, S., Shimojo, M., and Watanabe, S. (1995). Pain-related somatosensory evoked magnetic fields. Electroencephalogr. Clin. Neurophysiol. 95, 463-474.

Kobayashi, K., Winberry, J., Liu, C. C., Treede, R. D., and Lenz, F. A. (2009). A painful cutaneous laser stimulus evokes responses from single neurons in the human thalamic principal somatic sensory nucleus ventral caudal - Vc. J. Neurophysiol. 101, 2210-2217.

Kong, J., Loggia, M. L., Zyloney, C., Tu, P., Laviolette, P., and Gollub, R. L. (2010). Exploring the brain in pain: activations, deactivations and their relation. Pain 148, 257-267.

Kong, J., White, N. S., Kwong, K. K., Vangel, M. G., Rosman, I. S., Gracely, R. H., Gollub, R. L. (2006). Using fMRI to dissociate sensory encoding from cognitive evaluation of heat pain intensity. Hum. Brain Mapp. 27, 715-721.

Korzeniewska, A., Crainiceanu, C. M., Kus, R., Franaszczuk, P. J., and Crone, N. E. (2008). Dynamics of event-related causality in brain electrical activity. Hum. Brain Mapp. 29, 1170-1192.

Korzeniewska, A., Manczak, M., Kaminski, M., Blinowska, K. J., and Kasicki, S. (2003). Determination of information flow direction among brain structures by a modified directed transfer function (dDTF) method. J. Neurosci. Methods 125 , 195-207.

Lee, J., Dougherty, P. M., Antezana, D., and Lenz, F. A. (1999). Responses of neurons in the region of human thalamic principal somatic sensory nucleus to mechanical and thermal stimuli graded into the painful range. J. Comp. Neurol. 410, 541-555.

Lefaucher, J. P. (2008). "TMS and pain," in Handbook of Transcranial Stimulation, eds E. M. Wassermann, C. M. Epstein, U. Ziemann, V. Walsh, T. Paus and S. H. Lisanby (New York, NY: Oxford), 717-736.

Lenz, F. A. (2006). "Neurosurgical procedures for neuropathic pain," in Pain, eds T. S. Jensen and F. Cervero (Amsterdam: Elsevier), 869-886.

Lenz, F. A., Casey, K. L., Jones, E. G., and Willis, W. D. Jr. (2010). The Human Pain System: Experimental 
and Clinical Perspectives. NY: Cambridge University Press.

Lenz, F. A., Ohara, S., Gracely, R. H., Dougherty, P. M., and Patel, S. H. (2004). Pain encoding in the human forebrain: binary and analog exteroceptive channels. J. Neurosci. 24, 6540-6544.

Lenz, F. A., Rios, M., Zirh, A., Chau, D., Krauss, G., and Lesser, R. P. (1998). Painful stimuli evoke potentials recorded over the human anterior cingulate gyrus. J. Neurophysiol. 79, 2231-2234.

Lenz, F. A., Seike, M., Lin, Y. C., Baker, F. H., Rowland, L. H., Gracely, R. H., and Richardson, R. T. (1993). Neurons in the area of human thalamic nucleus ventralis caudalis respond to painful heat stimuli. Brain Res. 623, 235-240.

Leo, R. J., and Latif, T. (2007). Repetitive transcranial magnetic stimulation (rTMS) in experimentally induced and chronic neuropathic pain: a review. J. Pain 8, 453-459.

Levit-Binnun, N., Handzy, N. Z., Moses, E., Modai, I., and Peled, A. (2007). Transcranial magnetic stimulation at M1 disrupts cognitive networks in schizophrenia. Schizophr. Res. 93, 334-344.

Liu, C. C., Crone, N. E., Franaszczuk, P. J., Cheng, D., Schretlen, D. S., and Lenz, F. A. (2011a). Fear conditioning is associated with dynamic directed functional interactions between and within the human amygdala, hippocampus, and frontal lobe. Neuroscience 189, 359-369.

Liu, C. C., Ohara, S., Franaszczuk, P. J., and Lenz, F. A. (2011b). Attention to painful cutaneous laser stimuli evokes directed functional connectivity between activity recorded directly from human pain-related cortical structures. Pain 152, 664-675.

Liu, C. C., Ohara, S., Franaszczuk, P., Crone, N., and Lenz, F. A. (2011c). Attention to painful cutaneous laser stimuli evokes directed functional interactions between human sensory and modulatory pain-related cortical areas. Pain 152, 2781-2791.

Liu, C. C., Ohara, S., Franaszczuk, P. J., Zagzoog, N., Gallagher, M., and Lenz, F. A. (2010). Painful stimuli evoke potentials recorded from the medial temporal lobe in humans. Neuroscience 165, 1402-1411.

Melzack, R. (1990). Phantom limbs and the concept of a neuromatrix. Trends Neurosci. 13, 88-92.

Melzack, R., and Casey, K. L. (1968). "Sensory, motivational, and central control determinants of pain," in The Skin Senses, ed D. Kenshalo (Springfield, IL: Thomas), 423-443.

Mohler, H. (2009). Role of GABAA receptors in cognition. Biochem. Soc. Trans. 37, 1328-1333.

Mohler, H., Rudolph, U., Boison, D., Singer, P., Feldon, J., and Yee, B. K. (2008). Regulation of cognition and symptoms of psychosis: focus on $\operatorname{GABA}(\mathrm{A})$ receptors and glycine transporter 1. Pharmacol. Biochem. Behav. 90, 58-64.

Montes, C., Magnin, M., Maarrawi, J., Frot, M., Convers, P., Mauguiere, F., and Garcia-Larrea, L. (2005). Thalamic thermo-algesic transmission: ventral posterior (VP) complex versus VMpo in the light of a thalamic infarct with central pain Pain 113, 223-232.

Ohara, S., Crone, N. E., Weiss, N., Kim, J. H., Lenz, F. A. (2008). Analysis of synchrony demonstrates that the presence of "pain networks" prior to a noxious stimulus can enable the perception of pain in response to that stimulus. Exp. Brain Res. 185, 353-358.

Ohara, S., Crone, N. E., Weiss, N., and Lenz, F. A. (2004a). Attention to a painful cutaneous laser stimulus modulates electrocorticographic event-related desynchronization in humans. Clin. Neurophysiol. 115, 1641-1652.

Ohara, S., Crone, N. E., Weiss, N., and Lenz, F. A. (2006). Analysis of synchrony demonstrates 'pain networks' defined by rapidly switching, task-specific, functional connectivity between pain-related cortical structures. Pain 123 244-253.

Ohara, S., Crone, N. E., Weiss, N., Treede, R. D., and Lenz, F. A. (2004b). Amplitudes of laser evoked potential recorded from primary somatosensory, parasylvian and medial frontal cortex are graded with stimulus intensity. Pain 110, 318-328.

Ohara, S., Crone, N. E., Weiss, N., Treede, R. D., and Lenz, F. A. (2004c). Cutaneous painful laser stimuli evoke responses recorded directly from primary somatosensory cortex in awake humans. $J$. Neurophysiol. 91, 2734-2746.

Ohara, S., Crone, N. E., Weiss, N., Vogel, H., Treede, R. D., and Lenz, F. A. (2004d). Attention to pain is processed at multiple cortical sites in man. Exp. Brain Res. 156, 513-517.

Ohara, S., and Lenz, F. A. (2003). Medial lateral extent of thermal and pain sensations evoked by microstimulation in somatic sensory nuclei of human thalamus. J. Neurophysiol. 90, 2367-2377.

Ohara, S., Taghva, A., Kim, J. H., and Lenz, F. A. (2007). Spontaneous low threshold spike bursting in awake humans is different in different lateral thalamic nuclei. Exp. Brain Res. $180,280-281$.

Patel, S., Ohara, S., Dougherty, P. M., Gracely, R. H., and Lenz, F. A. (2006). Psychophysical elements of place and modality specificity in the thalamic somatic sensory nucleus (ventral caudal, vc) of awake humans. J. Neurophysiol. 95 , 646-659.

Peyron, R., Garcia-Larrea, L., Gregoire, M. C., Costes, N., Convers, P., Lavenne, F., Mauguiere, F., Michel, D., and Laurent, B. (1999). Haemodynamic brain responses to acute pain in humans: sensory and attentional networks. Brain 122 (Pt 9), 1765-1780.

Ploghaus, A., Tracey, I., Gati, J. S., Clare, S., Menon, R. S., Matthews, P. M., Rawlins, J. N. (1999). Dissociating pain from its anticipation in the human brain. Science 284 , 1979-1981.

Ploner, M., Freund, H.-J., and Schnitzler, A. (1999). Pain affect without pain sensation in a patient with a postcentral lesion. Pain 81 , 211-214.

Ploner, M., Schoffelen, J. M., Schnitzler, A., and Gross, J. (2009). Functional integration within the human pain system as revealed by Granger causality. Hum. Brain Mapp. 30, 4025-4032.

Porcello, D. M., Smith, S. D., and Huguenard, J. R. (2003). Actions of U-92032, a T-type Ca2+ channel antagonist, support a functional linkage between $\mathrm{I}(\mathrm{T})$ and slow intrathalamic rhythms. $J$. Neurophysiol. 89, 177-185.

Price, D. D. (2000). Psychological and neural mechanisms of the affective dimension of pain. Science 288 1769-1772.

Rainville, P., Bushnell, M. C., and Duncan, G. H. (2000). "PET studies of the subjective experience of pain," in Pain Imaging, eds K. L. Casey and M. C. Bushnell (Seattle: IASP Press), 123-156.

Rainville, P., Carrier, B., Hofbauer, R. K., Bushnell, M. C., and Duncan, G. H. (1999). Dissociation of sensory and affective dimensions of pain using hypnotic modulation. Pain 82, 159-171.

Rasche, D., Rinaldi, P. C., Young, R. F., and Tronnier, V. M. (2006). Deep brain stimulation for the treatment of various chronic pain syndromes. Neurosurg. Focus 21, E8.
Rios, M., Treede, R., Lee, J., and Lenz, F. A. (1999). Direct evidence of nociceptive input to human anterior cingulate gyrus and parasylvian cortex. Curr. Rev. Pain 3, 256-264.

Rodriguez, E., George, N., Lachaux, J. P., Martinerie, J., Renault, B., and Varela, F. J. (1999). Perception's shadow: long-distance synchronization of human brain activity. Nature 397, 430-433

Rudolph, U., and Mohler, H. (2006). GABA-based therapeutic approaches: GABAA receptor subtype functions. Curr. Opin. Pharmacol. 6, 18-23.

Schuurman, P. R., Bosch, D. A. Bossuyt, P. M., Bonsel, G. J., van Someren, E. J., de Bie, R. M., and Speelman, J. D. (2000). A comparison of continuous thalamic stimulation and thalamotomy for suppression of severe tremor. $N$. Engl. J. Med. 342, 461-468.

Shajahan, P. M., Glabus, M. F., Steele, J. D., Doris, A. B., Anderson, K., Jenkins, J. A., Gooding, P. A., and Ebmeier, K. P. (2002). Left dorso-lateral repetitive transcranial magnetic stimulation affects cortical excitability and functional connectivity, but does not impair cognition in major depression. Prog. Neuropsychopharmacol. Biol. Psychiatry 26, 945-954.

Sherman, S. M., and Guillery, R. W. (2001). Exploring the Thalamus and its Role in Cortical Function. New York, NY: Oxford University Press.

Singer, W., and Gray, C. M. (1995). Visual feature integration and the temporal correlation hypothesis. Annu. Rev. Neurosci. 18, 555-586.

Sirigu, A., Mottolese, C., and Desmurget, M. (2010). Response to comment on "movement intention after parietal cortex stimulation in humans". Science 327, 1200-d.

Starr, C. J., Sawaki, L., Wittenberg, G. F., Burdette, J. H., Oshiro, Y., Quevedo, A. S., and Coghill, R. C. (2009). Roles of the insular cortex in the modulation of pain: insights from brain lesions. J. Neurosci. 29, 2684-2694.

Steriade, M., Jones, E. G., and McCormick, D. A. (1997a). "Thalamic, organization and chemical neuroanatomy," in Thalamus, Vol. 1, eds M. Steriade, E. G., Jones, and D. A., McCormick (Amsterdam: Elsevier), 269-338.

Steriade, M., Jones, E. G., and McCormick, D. A. (1997b). Thalamus Organisation and Function. Amsterdam: Elsevier.

Strigo, I. A., Duncan, G. H., Boivin, M., and Bushnell, M. C. (2003). 
Differentiation of visceral and cutaneous pain in the human brain. $J$. Neurophysiol. 89, 3294-3303.

Talbot, J. D., Villemure, J. G., Bushnell, M. C., and Duncan, G. H. (1995). Evaluation of pain perception after anterior capsulotomy: a case report. Somatosens. Mot. Res. 12, 115-126.

Tarkka, I. M., and Treede, R. D. (1993). Equivalent electrical source analysis of pain-related somatosensory evoked potentials elicited by a $\mathrm{CO} 2$ laser. J. Clin. Neurophysiol. 10, 513-519.

Topper, R., Foltys, H., Meister, I. G., Sparing, R., and Boroojerdi, B. (2003). Repetitive transcranial magnetic stimulation of the parietal cortex transiently ameliorates phantom limb pain-like syndrome. Clin. Neurophysiol. 114, 1521-1530.

Tsubokawa, T., Katayama, Y., and Hirayama, T. (1987). Effects of thalamic sensory relay nucleus stimulation on trigeminal subnucleus caudalis neurons in the cat abnormal bursting hyperactivity after trigeminal rhizotomy. Neurol. Med. Chir. (Tokyo) 27, 601-606.

Tsubokawa, T., Katayama, Y., Yamamoto, T., Hirayama, T., and Koyama, S. (1991). Treatment of thalamic pain by chronic motor cortex stimulation. Pacing Clin. Electrophysiol. 14, 131-134.

Valeriani, M., Rambaud, L., and Mauguiere, F. (1996). Scalp topography and dipolar source modelling of potentials evoked by $\mathrm{CO} 2$ laser stimulation of the hand. Electroencephalogr. Clin. Neurophysiol. 100, 343-353.

Veldhuijzen, D. S., Greenspan, J. D., Kim, J. H., and Lenz, F. A. (2009). Altered pain and thermal sensation in subjects with isolated parietal and insular cortical lesions. Eur. J. Pain 14, e535-e1-e535-e11

von der Malsburg, C. (1995). Binding in models of perception and brain function. Curr. Opin. Neurobiol. 5, 520-526.

Walter, B. L., and Vitek, J. L. (2004). Surgical treatment for Parkinson's disease. Lancet Neurol. 3, 719-728.
Wassermann, E. M., Epstein, C. M., Ziemann, U., Paus, T., and Lisanby, S. H. (2010). The Oxford Handbook of Transcranial Magnetic Stimulation. New York, NY: Oxford.

Wassermann, E. M., and Lisanby, S. H. (2001). Therapeutic application of repetitive transcranial magnetic stimulation: a review. Clin. Neurophysiol. 112, 1367-1377.

Weiner, N. (1956). "The theory of prediction," in Modern Mathematics for Engineers, ed E. Bechenbach (New York, NY: McGraw-Hill), 165-190.

Wichmann, T., and DeLong, M. R. (1996). Functional and pathophysiological models of the basal ganglia. Curr. Opin. Neurobiol. 6, 751-758.

Zygierewicz, J., Durka, P. J., Klekowicz, H., Franaszczuk, P. J., and Crone, N. E. (2005). Computationally efficient approaches to calculating significant ERD/ERS changes in the time-frequency plane. J. Neurosci. Methods 145, 267-276.

Zygierewicz, J., Mazurkiewicz, J., Durka, P. J., Franaszczuk, P. J., and Crone, N. E. (2006). Estimation of short-time cross-correlation between frequency bands of event related EEG. J. Neurosci. Methods 157, 294-302.

Conflict of Interest Statement: The authors declare that the research was conducted in the absence of any commercial or financial relationships that could be construed as a potential conflict of interest.

Received: 10 August 2011; accepted: 19 November 2011; published online: 05 December 2011.

Citation: Liu CC, Franaszczuk P, Crone NE, Jouny C and Lenz FA (2011) Studies of properties of "Pain Networks" as predictors of targets of stimulation for treatment of pain. Front. Integr. Neurosci. 5:80. doi: 10.3389/fnint.2011.00080 Copyright (c) 2011 Liu, Franaszczuk, Crone, Jouny and Lenz. This is an openaccess article distributed under the terms of the Creative Commons Attribution Non Commercial License, which permits non-commercial use, distribution, and reproduction in other forums, provided the original authors and source are credited. 